\title{
HYGROTHERMAL SIMULATION: USE FOR SERVICE LIFE PREDICTION AND MAINTENANCE OF FAÇADES
}

\author{
MATHEUS NASCIMENTO ${ }^{1}$, JEFFERSON GONÇALVES PEREIRA ${ }^{2}$, GUSTAVO LIRA ALVES ${ }^{2}$, \\ VAMBERTO DOS SANTOS FILHO ${ }^{3} \&$ ANDRÉ A. NÓBREGA DANTAS ${ }^{4}$ \\ ${ }^{1}$ Centro Universitário Euro-Americano (UNIEURO), Brazil \\ ${ }^{2}$ Gonçalves Engineering Company, Brazil \\ ${ }^{3}$ Instituto de Educação Superior de Brasília (IESB), Brazil \\ ${ }^{4}$ Instituto Federal de Goiás (IFG), Brazil
}

\begin{abstract}
The façade cladding of a building is a system responsible for providing and maintaining the comfort of the indoor environment as both thermal and acoustic insulation, as well as protecting the building envelope from weathering agents. Moreover, these systems have visual, aesthetic and cultural purposes. One of the most used façade coatings is ceramic tile, which is able to provide appropriate resistance to weather, but with an elevated rate of degradation. Such downside results are the loss of performance, quality and that the building may not reach its estimated service life. For this reason, the adaptation of architectural design to the natural environment is important. The present paper aims at measuring the action of weather agents on a sample of three buildings under construction in Brasília, Brazil. We used hygrothermal simulation software, WUFI Pro 6.0, to quantify the results for wind-driven rain, radiation and temperature on the north, south, east and west orientation of these buildings. The results of global radiation and wind-driven rain presented the same order of incidence, and the most critical values occurred during the dry period, for the north and west orientations. The variations of surface temperature in general reached maximum values on the north and west façades. A temperature gradient was also quantified, revealing a similar trend to the previous results. Furthermore, results were useful in identifying maintenance strategies and for service life prediction for the three buildings' casings, and show advances in the design phase, by learning from nature and traditional construction techniques.

Keywords: Brazil, building façade, building degradation, building design, ceramic tile, construction, hygrothermal simulation, maintenance, tiled exteriors, weathering.
\end{abstract}

\section{INTRODUCTION}

A ceramic tile coating is one of the main types of systems used on building façades. Its broad use is explained not only by the aesthetics, but also by the resistance and durability provided, when compared with mortar coatings; however, both new and old construction with this solution do present constant anomalies, originated in different ways, through planning, design, execution, low-quality materials, weather, incorrect building use, and lack of maintenance [1].

Within this context, degradation can be defined as a process whereby one or more properties of the materials are affected by the action of degradation factors, causing a reduction in the level of performance [2]. Degradation factors are those that adversely affect the performance of the buildings, and they are: atmospheric, biological, load, incompatibility and due to use [3]. In its initial phase, the degradation process may not be noticeable; but when the anomalies become evident, they start a decision process that verifies the need to intervene with maintenance [4]. The main pathological manifestations that present in ceramic tile coatings from different degradation factors are: coating detachment, cracking, efflorescence, sealing failure, and staining, to name a few.

When analysing the relationship between degradation and performance of the systems in a building, the importance of performing maintenance activities becomes evident. Such activities may have two main origins: the preservation of material durability in a proactive 
way (preventive); and corrective, initiated after the appearance of pathological manifestations or when the system no longer performs its function satisfactorily [5]. For ceramic tile coatings, many aspects of maintenance need to be observed. In a preventive way, periodic inspections to verify the stability of the coatings should be in place. In addition, approximately every five years, users are responsible for replacing movement joints [6]. For the corrective measures, users need to replace ceramic tile that detaches; correct points with cracks, sealing failures; target maintaining the service life, durability; and protecting users.

One of the main factors responsible for generating pathological manifestations in the buildings' façades; and consequently, reducing performance are weather agents, which can cause physical and chemical alterations in the buildings and in their components. Radiation, wind-driven rain and variations of temperature are important examples of these degradation factors [7]. Therefore, the knowledge of the conditions of façades' exposure to weather factors allows for a broader understanding of the interactions between nature's agents and degradation processes throughout the service life of the building. In this way, it is possible to adapt architectural design to the natural environment, learning from nature and traditional construction techniques in Brazil and many other countries.

Software packages for hygrothermal simulation can be used as a tool for quantification of the weather agents [8]. One example of these packages of software is WUFI [9], developed by the Fraunhofer Institute for Building Physics (IBP). With this tool, the user can calculate the transient transport of heat and moisture in different construction materials. The hourly output data can be presented in terms of the systems (variations of temperature and moisture properties); and in consideration of the environment conditions (radiation, temperature, moisture, wind-driven rain). The results can be combined with the degradation process in a post-processing simulation; in order to associate the damages caused by temperature and moisture, and how they act in the degradation of the studied systems [10].

The goal of this paper is to measure the action of weather agents in a sample of three buildings under construction in Brasília, Brazil, using hygrothermal simulation software.

\section{METHODOLOGY}

The method is based on the use of $\mathrm{WUFI}^{\circledR}$ Pro 6.0 software as a tool for quantification of weather agents and for assessing the degradation of the façades studied. First, our selection of the buildings in Brasilia, Brazil was established with three buildings under construction having ceramic tile coating on their façades, taking into account different colour bands: light, medium and dark. After that, the three cases were simulated with WUFI and the results were presented in terms of quantification of the weather agents and the buildings' response, which allowed the influence in the degradation process.

\subsection{Building casing}

In this study, we targeted buildings located in Brasília, Brazil, where the city plan and regulations limit all the residential buildings in the central area to six floors. The façades of the chosen samples are totally or partially coated with ceramic tile. The selection of samples was decided by means of surveys, where we searched for buildings under construction with colours used in the light, medium and dark bands of colours. The three buildings, named as $\mathrm{A}, \mathrm{B}$ and $\mathrm{C}$; are represented in Figs 1-3. 


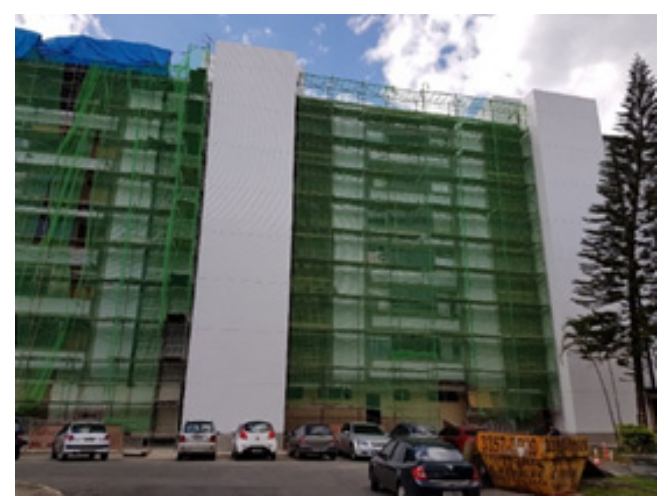

Figure 1: Building A (light colour tile used).

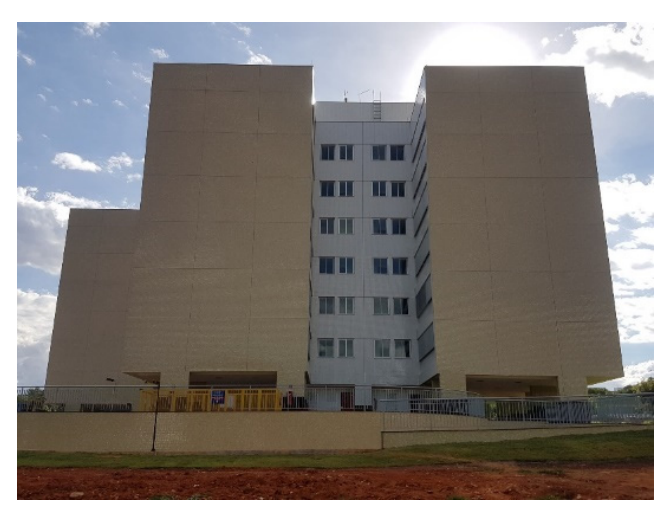

Figure 2: Building B (medium colour used).

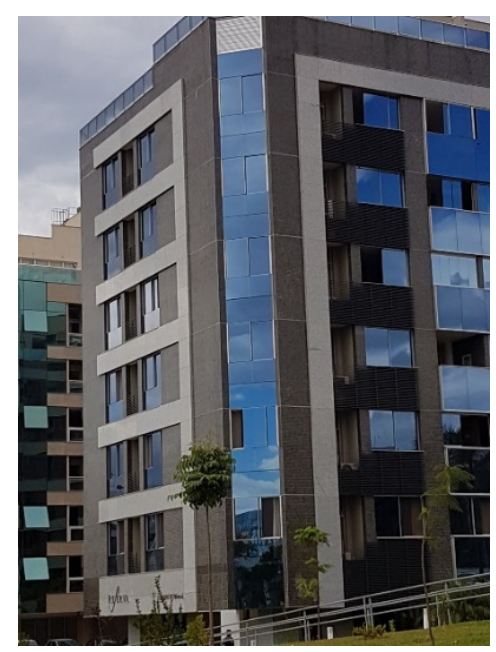

Figure 3: Building C (dark colour used). 


\subsection{Simulation}

For the hygrothermal simulation using the WUFI PRO 6.0 software, it is necessary to determine parameters according to the place of study, for the insertion of data. The characteristics of the buildings should be defined, such as: materials, orientation of façades, wind-driven rain, coefficient of absorptivity $(\alpha)$, simulation period, and outdoor and indoor climate [8]. The software uses a calculation method based on transient regime and it is possible to obtain hourly output data of the climate of the exterior and properties related to the temperature and moisture of the studied materials [9].

Fig. 4 shows the constructive element adopted and represents the ceramic tile coating on the façades of the three buildings studied [9], [11].

The WUFI software contains an extensive database of properties of construction materials, and the main definitions of parameters [9] of input data below (general definitions) and in Table 1 (materials' definitions):

- Wind-driven rain: using the $\mathrm{WUFI}^{\circledR}$ method of calculation, with a reduction coefficient of 0.7 ;

- Height: high building from 10 to $20 \mathrm{~m}$ (representing six floors);

- Heat resistance: Exterior surface $-0.04 \mathrm{~m}^{2} \mathrm{~K} / \mathrm{W}$; Interior surface $-0.13 \mathrm{~m}^{2} \mathrm{~K} / \mathrm{W}$ [6];

- Absorptivity $(\alpha)$ : Building A - 0.3; Building B - 0.5; Building $\mathrm{C}-0.7$ [6] represents the amount of radiation energy absorbed;

- Initial conditions: initial relative humidity $(80 \%)$ and temperature $\left(25^{\circ} \mathrm{C}\right)[10]$;

- Simulation period: $01 / 01 / 2017$ to $31 / 12 / 2020$, using data referring to the last year, when the initial moisture stabilization had occurred [11];

- Climatic data: TMY (Typical Meteorological Year) file for Brasilia, Brazil [12];

- Indoor climate: according to [10].

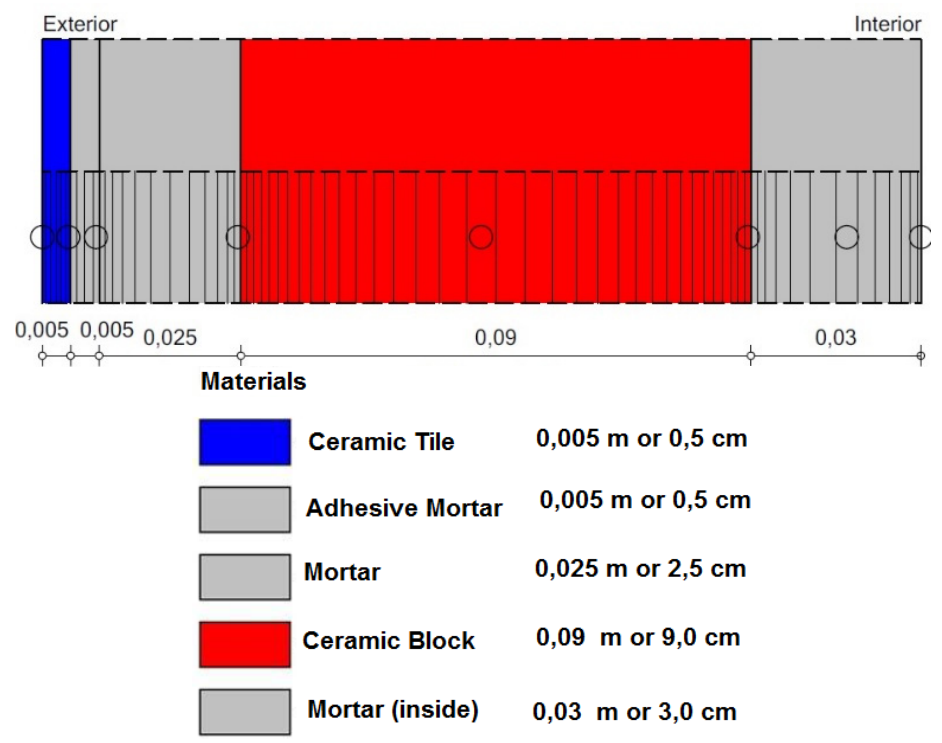

Figure 4: Ceramic tile coating system used (layer size represented in meters), as per [9] and [11]. 
Table 1: Materials parameters from [9] and [11].

\begin{tabular}{|l|c|c|c|c|c|}
\hline & $\begin{array}{c}\text { Bulk } \\
\text { density }\end{array}$ & Porosity & $\begin{array}{c}\text { Specific heat } \\
\text { capacity }\end{array}$ & $\begin{array}{c}\text { Thermal } \\
\text { conductivity }\end{array}$ & $\begin{array}{c}\text { Water vapor } \\
\text { diffusion } \\
\text { resistance factor }\end{array}$ \\
\hline Units & $\mathrm{kg} / \mathrm{m}^{3}$ & $\mathrm{~m}^{3} / \mathrm{m}^{3}$ & $\mathrm{~J} / \mathrm{kg} . \mathrm{K}$ & $\mathrm{W} / \mathrm{m} . \mathrm{K}$ & {$[-]$} \\
\hline Ceramic tile & 1,730 & 0.290 & 868 & 0.490 & 116 \\
\hline $\begin{array}{l}\text { Adhesive } \\
\text { mortar }\end{array}$ & 1,450 & 0.260 & 850 & 0.800 & 18 \\
\hline $\begin{array}{l}\text { External and } \\
\text { internal mortar }\end{array}$ & 1,755 & 0.210 & 850 & 0.800 & 28 \\
\hline Ceramic block & 578 & 0.486 & 850 & 0.158 & 23 \\
\hline
\end{tabular}

\subsection{Weather conditions}

The climatic archive (.epw) was used, from the measurement scale of the National Institute of Meteorology in Brazil (INMET) [12]. This took place in the 2000-2010 period, and the Laboratory of Energy Efficiency in Buildings (LABEEE-UFSC) reasserted this data in 2016. The file contains 8,760 hours of weather data (radiation, temperature, wind-driven rain and relative humidity), proven to be representative for Brasília, Brazil [13].

The archive provided by LABEEE-UFSC is composed of climatic variations; it is possible to characterize the cyclical and seasonal behaviour of climate throughout the year, taking into consideration the average values, maximums and frequencies of occurrence due to hourly data provided from the software [13]. Fig. 5 demonstrates a summary of the climate file.

By analysing the graph provided by the WUFI Pro 6.0 software (Fig. 5), the solar radiation incidence is higher in the northern orientation $\left(1,015 \mathrm{kWh} / \mathrm{m}^{2}\right)$; followed by: eastern $\left(917 \mathrm{kWh} / \mathrm{m}^{2}\right)$; western $\left(911 \mathrm{kWh} / \mathrm{m}^{2}\right)$; and southern $\left(639 \mathrm{kWh} / \mathrm{m}^{2}\right)$ orientations. The winddriven rain follows the same incidence index in the façades, with a normal rain amount of $1,093 \mathrm{~mm} /$ year. The mean wind speed is $2.46 \mathrm{~m} / \mathrm{s}$, the maximum temperatures are: $32.7^{\circ} \mathrm{C}$; $21.1^{\circ} \mathrm{C}$ for mean, and $11.2^{\circ} \mathrm{C}$ for minimum. The relative humidity presented: $97 \%$ for the maximum, $66 \%$ for the mean, and $17 \%$ for the minimum.

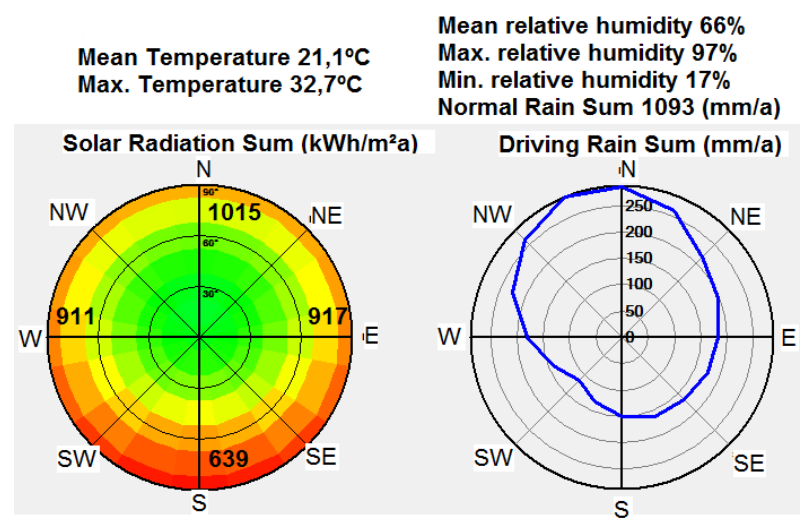

Figure 5: Climate from Brasília [9]. 


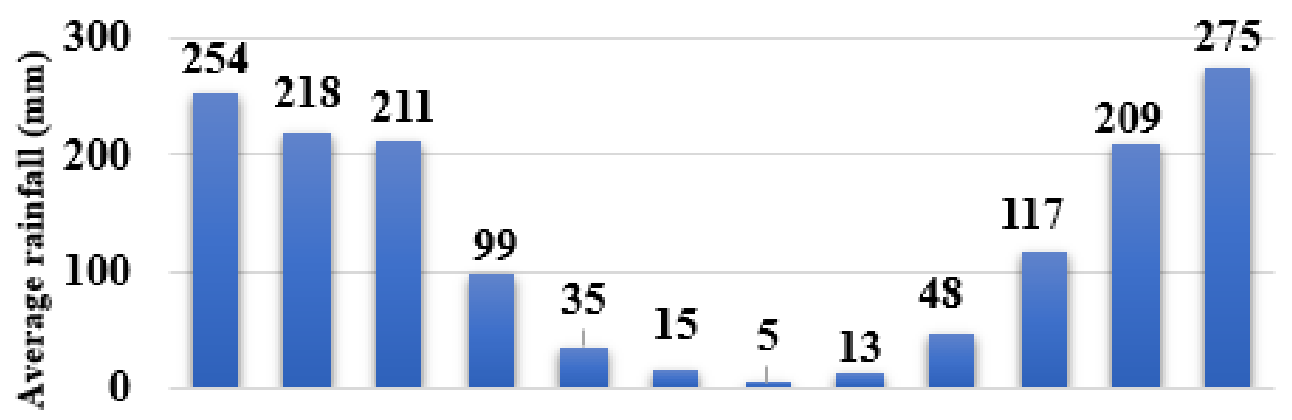

Jan. Feb. Mar. Apr. May June July Aug. Sept. Oct. Nov. Dec.

Figure 6: Average rainfall in Brasília [14].

In Brasília, the so-called drought months are from April to September, comprising a sixmonth dry period [14]. Whereas, the other six-month period (October to March) is the rainy season. Fig. 6 shows the monthly rainfall average in the Federative Union of Federal District, where the observation of the two above-mentioned periods during the year is evident.

\subsection{Output data}

One can extract output data from the WUFI on an hourly basis, for all parameters analysed and based on the WUFI instructions [9], which state that the hourly data will be about the distribution of temperature and heat fluxes in materials with temporal variations; and the moisture content $(\mathrm{g})$, relative humidity (\%), and distribution of moisture flow in the materials, considering temporal variations.

The post-processing step is associated with the application of the collected results of the simulations [10]:

- Wind-driven rain: rainfall on the surface of the façade due to the action of the wind on precipitation, for all studied buildings;

- Radiation: global value that affects all façades (north, south, east and west orientations);

- Surface temperature, and daily thermal amplitude for all buildings.

This study focused on the degradation of the envelopment of buildings, especially the degradation caused by weather actions such as wind-driven rain (moisture), solar radiation, and temperature variations.

\section{RESULTS AND DISCUSSION}

The rainy season in Brasilia occurs between September and April. According to a rainfall study [14]; May, June, July and August are the driest months of the year. The six rainiest months of the year (October, November, December, January, February and March) identified correspond to $92 \%$ of the total precipitation. Consequently, $8 \%$ of the total precipitation corresponds to the six driest months (April, May, June, July, August and September).

Using the data extracted from the WUFI 6.0 simulations, it was possible to obtain the incident wind-driven rain in the four cardinal directions. The order of incidence is: north $\left(143.03 \mathrm{~L} / \mathrm{m}^{2} ; 35.8 \%\right)$; east $\left(91.4 \mathrm{~L} / \mathrm{m}^{2} ; 22.9 \%\right)$; west $\left(89.89 \mathrm{~L} / \mathrm{m}^{2} ; 22.5 \%\right)$, and south $(74.79$ $\left.\mathrm{L} / \mathrm{m}^{2} ; 18.7 \%\right)$, as seen in Fig. 7 . 


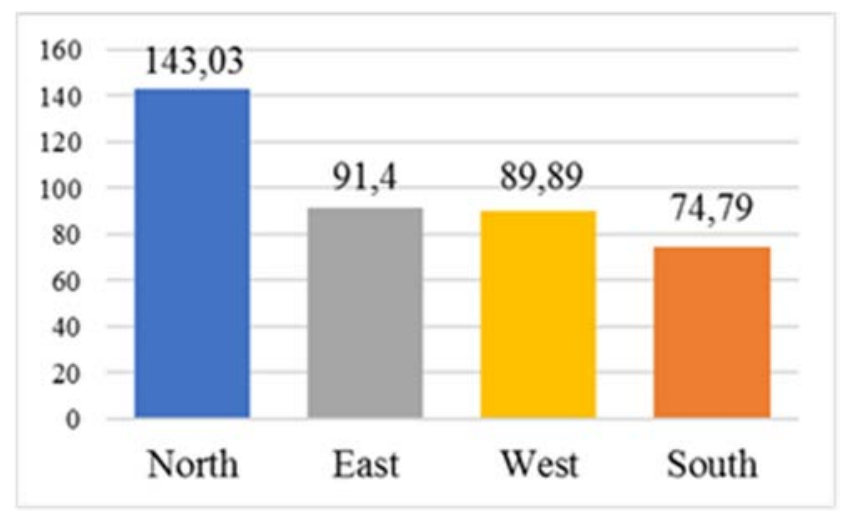

Figure 7: Wind-driven rain $\left(\mathrm{L} / \mathrm{m}^{2}\right)$ obtained from simulation (annual values).

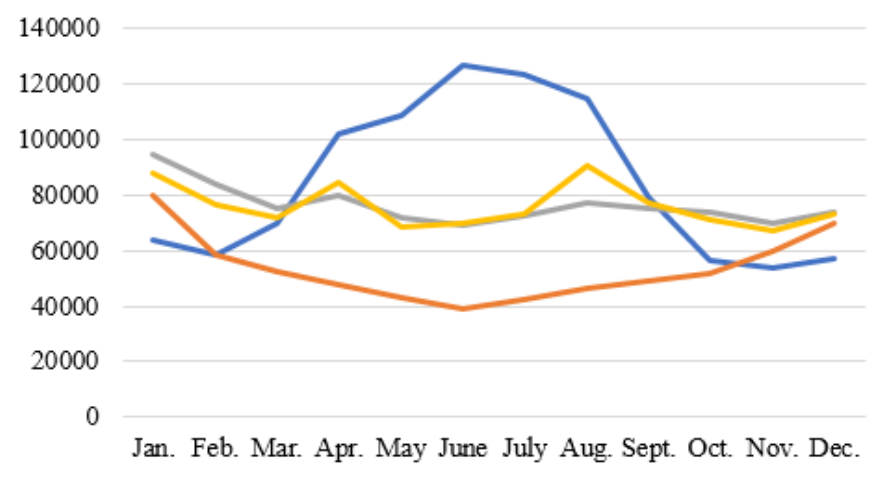

Figure 8: Radiation $\left(\mathrm{W} / \mathrm{m}^{2}\right)$ obtained from simulation with monthly values.

The results obtained by the simulation for global solar radiation are shown in Fig. 8 (monthly accumulated values) for the period of one year; in the north, south, east and west orientations.

One can observe that during the dry period (April to September), the northern façade receives the highest incidence of solar radiation (18.8\% of the total sum of all façades). A previous study [11] showed that the dry season is mainly responsible for the degradation of buildings, especially degradation caused by thermal variations. During the entire rainy period (October to March), the southern façade receives a higher incidence than the northern façade (except during March and October), but less than the eastern and western façades, according to Fig. 8. It is indisputable due to the evidence that differences occur in the seasonal effects in Brasília. The software proved to be a good tool for identifying these variances. In others studies, the software had already substantiated different kinds of climate change and variations [15].

When considered, the accumulated values the northern façade show it is the most critical side $(29.1 \%)$; followed by east $(26.3 \%)$; west $(26.2 \%)$, and south $(18.4 \%)$ orientations. This order is exactly the same as what is obtained with wind-driven rain values. 
Table 2: $\quad$ Superficial temperature $\left({ }^{\circ} \mathrm{C}\right)$ : average and maximum for the annual dry and rainy periods in Brasilia, Brazil.

\begin{tabular}{|c|l|c|cc|cc|}
\hline Building & $\begin{array}{l}\text { Cardinal } \\
\text { direction }\end{array}$ & $\begin{array}{c}\text { Average } \\
\text { annual }\end{array}$ & $\begin{array}{c}\text { Maximum } \\
\text { dry }\end{array}$ & $\begin{array}{c}\text { Average } \\
\text { dry }\end{array}$ & $\begin{array}{c}\text { Maximum } \\
\text { rainy }\end{array}$ & $\begin{array}{c}\text { Average } \\
\text { rainy }\end{array}$ \\
\hline \multirow{3}{*}{$\begin{array}{c}\text { A } \\
(\boldsymbol{\alpha}=\mathbf{0 . 3})\end{array}$} & North & 25.5 & 38.3 & 25.2 & 43.7 & 25.9 \\
& South & 24.5 & 38.3 & 25.3 & 37.9 & 23.8 \\
& East & 25.3 & 41.1 & 25.8 & 41.5 & 24.7 \\
& West & 25.3 & 46.0 & 25.7 & 44.3 & 24.8 \\
\hline \multirow{3}{*}{$\mathbf{(}=\mathbf{0 . 5})$} & North & 26.1 & 39.8 & 25.5 & 46.7 & 26.6 \\
& South & 24.9 & 39.7 & 25.7 & 39.0 & 24.1 \\
& East & 25.9 & 43.8 & 26.3 & 43.7 & 25.3 \\
& West & 25.8 & 49.1 & 26.1 & 46.6 & 25.4 \\
\hline $\mathbf{C}$ & North & 27.0 & 42.9 & 26.1 & 51.5 & 27.8 \\
$(\boldsymbol{\alpha}=\mathbf{0 . 7})$ & South & 25.5 & 42.1 & 26.3 & 40.7 & 24.6 \\
& East & 26.6 & 48.0 & 27.2 & 47.1 & 26.0 \\
& West & 26.5 & 54.1 & 26.9 & 50.2 & 26.2 \\
\hline
\end{tabular}

For temperature, the study used the maximum and average obtained on the surface of the buildings. The mean values of external surface temperature were presented for the annual, dry and rainy periods, and the maximum for the dry and rainy periods is shown in Table 2. It is paramount that the software provide hourly data for these parameters, but the present paper had focused on a macro analysis. Other studies have shown that the software is able to evaluate microclimates (inside and outside), considering the hourly data provided [11], [13]. Global solar radiation influences external surface temperature, the variation of external air temperature, and hygrothermal characteristics of the construction system, to name a few.

When analysing Table 2, one observes the behaviour of external surface temperature values, which vary throughout the year. Building A $(\alpha=0.3)$, had the lowest value (annual average) of $24.5^{\circ} \mathrm{C}$ for the southern façade; while the highest maximum annual average value was $27.0^{\circ} \mathrm{C}$ for Building $\mathrm{C}(\alpha=0.7)$ on the north façade. When analysing the annual average temperature of all the orientations, it was possible to classify the façades in descending order: north, east, west and south.

Scrutinizing the extremes of the maximum and minimum temperatures of the buildings, one realises that there was some variation between the maximum values of the façades. The maximum value was $54.1^{\circ} \mathrm{C}$, which occurred in the dry period on the western façade of Building $\mathrm{C}$ (absorbance -0.7). All other buildings also had the maximum temperature in the western orientation (the absorbances of 0.3 and 0.5 had values of $46.0^{\circ} \mathrm{C}$ and $49.1^{\circ} \mathrm{C}$, respectively). With the focus on the minimum values, it was observed that the values are constant for all façades studied $\left(13.3^{\circ} \mathrm{C}\right.$ for the rainy period and $17.4^{\circ} \mathrm{C}$ for the dry period).

Another way to investigate the temperature parameter is the value of $\Delta \mathrm{T}$. This can be calculated using the maximum (Tmax.daily). and minimum (Tmin.daily) surface temperatures differences during a day, according to eqn (1). 


$$
\Delta T=\text { Tmax.daily }- \text { Tmin.daily. }
$$

For this calculation, all the daily values of the three buildings studied and the maximum were taken into consideration, as well as average (annual, dry and rainy) periods, as shown in Table 3.

Table 3 shows that the maximum $\Delta \mathrm{T}$ value $\left(27.8^{\circ} \mathrm{C}\right)$ obtained for the dry period occurred for the northern façade. In the rainy season, the maximum $\left(29.6^{\circ} \mathrm{C}\right)$ occurs for the western façade. For both cases, the maximum values occur for Building $\mathrm{C}$, which has the highest absorbance $(\alpha)$. In this sense it is also possible to observe, as well as in the individually analysed temperature parameters, an increase in the values of $\Delta \mathrm{T}$ according to the growth of the absorbance presented by the buildings.

The minimum $\Delta \mathrm{T}$ values show little variation, even when the dry and rainy periods are compared. The mean values for the minimum variation observed were $2.5^{\circ} \mathrm{C}$ for the dry period and $3.6^{\circ} \mathrm{C}$ for the rainy season. With this, it is noticed that the minimum $\Delta \mathrm{T}$ of the rainy season increases in relation to the dry. This could have occurred due to the decrease of surface temperature of the façades caused by periods of higher incidence of rains.

The comparison of the maximum values between the dry and rainy periods reveals a greater difference of $\Delta \mathrm{T}$, especially for the northern orientation. In Building $\mathrm{C}$, for example, the difference reaches $7.6^{\circ} \mathrm{C}$. The comparison of two periods reveals a trend of higher averages in the dry period in the northern, western and eastern orientations.

The comparison on the results of radiation, wind-driven rain, temperature and $\Delta \mathrm{T}$, is a tool for observing that façades are mostly influenced by these parameters on the north, west and east; followed by lower values presented for the southern façades. This trend may influence a higher degradation of the north and west façades. This has also been observed in previews studies [11], [13]. With these results, it is clear that the WUFI software was able to quantify the weather incidence presented in the studied buildings. This software can be a tool used in the design of new buildings, as there is a great availability of climatic archives (.epw) for the whole world. This is a study that might be replicated; and consequently, generate good results for other cities and countries.

Table 3: Temperature gradient $\left(\Delta \mathrm{T}\right.$ in $\left.{ }^{\circ} \mathrm{C}\right)$ : Maximum and average temperatures for three tiled buildings during dry and rainy periods, and annually.

\begin{tabular}{|c|l|c|c|c|c|c|}
\hline Building & Orientation & $\begin{array}{c}\text { Average } \\
\text { annual }\end{array}$ & $\begin{array}{c}\text { Maximum } \\
\text { dry }\end{array}$ & $\begin{array}{c}\text { Average } \\
\text { dry }\end{array}$ & $\begin{array}{c}\text { Maximum } \\
\text { rainy }\end{array}$ & $\begin{array}{c}\text { Average } \\
\text { rainy }\end{array}$ \\
\hline & North & 11.9 & 18.6 & 14.0 & 14.0 & 9.8 \\
$\mathbf{A}$ & South & 10.2 & 14.5 & 10.6 & 14.1 & 9.8 \\
$(\boldsymbol{\alpha}=\mathbf{0 . 3})$ & East & 16.5 & 22.6 & 16.8 & 23.2 & 16.2 \\
& West & 12.6 & 18.3 & 13.6 & 19.6 & 11.6 \\
\hline \multirow{3}{*}{$\mathbf{B}$} & North & 14.7 & 23.2 & 17.8 & 17.0 & 11.7 \\
$(\boldsymbol{\alpha}=\mathbf{0 . 5})$ & South & 11.8 & 15.7 & 11.9 & 16.4 & 11.6 \\
& East & 13.5 & 18.9 & 13.8 & 18.9 & 13.2 \\
& West & 15.7 & 22.0 & 16.8 & 19.5 & 14.6 \\
\hline & North & 17.6 & 27.8 & 12.6 & 20.2 & 13.6 \\
$\mathbf{C}$ & South & 13.3 & 16.9 & 13.2 & 18.7 & 13.5 \\
$\mathbf{( \alpha = 0 . 7 )}$ & East & 16.5 & 22.6 & 16.8 & 23.2 & 16.2 \\
& West & 18.9 & 26.6 & 20.1 & 29.6 & 17.7 \\
\hline
\end{tabular}


The WUFI software proved to be useful for defining maintenance strategies, because it is possible to determine the most critical orientations due to climate change and these façades can be given special attention during the service life of the building. Movement joints need to have special definitions, both in the design stage and in maintenance, mainly for northern and western façades, for instance, considering the results obtained. Due to the most critical thermal variations presented in theses façades, the periodic inspections that are recommended could also have the time span decreased.

\section{CONCLUSIONS}

Our results showed great temperature differences between the absorbances. The seasonality of the climate also was a determining factor in the degradation of the façades.

Temperature and thermal amplitude $(\Delta \mathrm{T})$ responses showed that the most critical incidents occurred on northern and western orientations, which may have a tendency to possess higher rates of degradation, which was already proven by previous studies. In Brasilia, the dry season presented higher values in the great majority of cases, when compared to the rainy season, both for surface temperature and $\Delta \mathrm{T}$, which may be the determinant factors for the evolution of façade degradation in these orientations; thus, to the dry season may be attributed the greatest responsibility for degradation.

The union of the studied parameters (absorbance and climatic factors like radiation, winddriven rain and temperature) is shown as a determinant for degradation. Since façades with higher absorbances had the most critical values presented, for the west and the north orientations (in terms of temperature), and for both wind-driven rain and radiation, these façades had higher incidences. As such, the necessity of adaptation of material characteristics is evidenced and adaptation of the design phase, due to the natural environment.

As was proven, the software can be used as a tool in the design phase, during calculation of the service life of a building (indicating the façades most affected by the climate), and to assist in the implementation of maintenance actions. Furthermore, the results can be used as a way of comparing the degradation presented by the façades.

As recommendations for future papers, the application of this same methodology is suggested for other cities worldwide; and we suggest a more systematic evaluation, considering other possible sources of problems, such as: use, lack of maintenance, execution, etc. It is also suggested to do tests with other construction systems in hygrothermal simulation, such as with concrete, mortar and other coatings.

\section{ACKNOWLEDGEMENTS}

The authors would like to thank Fundação de Apoio à Pesquisa do Distrito Federal (FAPDF), Centro Universitário UNIEURO, Instituto de Educação Superior de Brasília (IESB) and Instituto Federal de Goiás (IFG-Formosa).

\section{REFERENCES}

[1] Medeiros, J.S. \& Sabbtini, F.H., Design and Installation Technology of Ceramic Tile Building Façade, São Paulo: EPUSP, 1999.

[2] British Standard Institution, BS ISO 15686-8 Buildings and constructed assets. Service life planning. Part 8: Reference service life and service-life estimation, London, 2008.

[3] British Standard Institution, BS ISO 15686-2 Buildings and constructed assets. Service life planning. Part 2: Service life prediction procedures, London, 2012.

[4] Souza, J.S., Evolution of façade degradation - effect of degradation agents and elements constituents. Master's thesis, University of Brasília, Brazil. 2016. 
[5] Flores-Colen, I., Methodology for in-service performance assessment of rendering façades for predictive maintenance. PhD thesis, Technical University of Lisbon, Lisbon, Portugal, 2009.

[6] Brazilian Association of Technical Standards, NBR 15575-1: Housing Buildings Performance. General requirements, Rio de Janeiro, 2013.

[7] Freitas, V.P. \& Vaz Sá, A., Cementitious adhesives' performance during service life. 10th DBMC International Conference On Durability of Building Materials and Components, Lyon, France, 2005.

[8] Nascimento, M., Bauer, E., Souza, J. \& Zanoni, V., Study of degradation in building façades by climatic agents. Euro-American Congress REHABEND, Burgos, 2016.

[9] WUFI Pro 6.0, Fraunhofer Institute for Building Physics (IBP), Holzkirchen, Germany, 2017.

[10] Deutsches Institut Für Normung, DIN EN 15026 Hygrothermal performance of building components and building elements - Assessment of moisture transfer by numerical simulation, CEN, Brussels, Belgium, 2007.

[11] Nascimento, M.L.M., Application of hygrothermal simulation on investigation of building façades degradation. Master's thesis, University of Brasília, Brazil, 2016.

[12] Roriz, M., Climatic Archives of Brazilian Municipalities. ANTAC - National Association of Built Environment Technology. Working Group on Comfort and Energy Efficiency of Buildings, São Carlos, SP, Brazil, 2012.

[13] Zanoni, V.A.G., Influence of climatic agents of degradation on hygrothermal behavior of façades in Brasilia. PhD thesis, University of Brasília, Brazil, 2015.

[14] Cardoso, M.R.D., Marcuzzo, F. \& Barros, J., Climatic classification of Köppen-Geiger for the states of Goiás and the Federal district. ACTA Geográfica, 8(16), pp. 40-55, 2014.

[15] Sousa, J. do N., Dias, S., Lucenas, R. \& Nascimento, M.L.M., The hygrothermal simulation in the study of façades' degradation in Teresina-PI. 6th Conference about Pathology and Rehabilitation of Buildings, Rio de Janeiro, Brazil, 2018. 